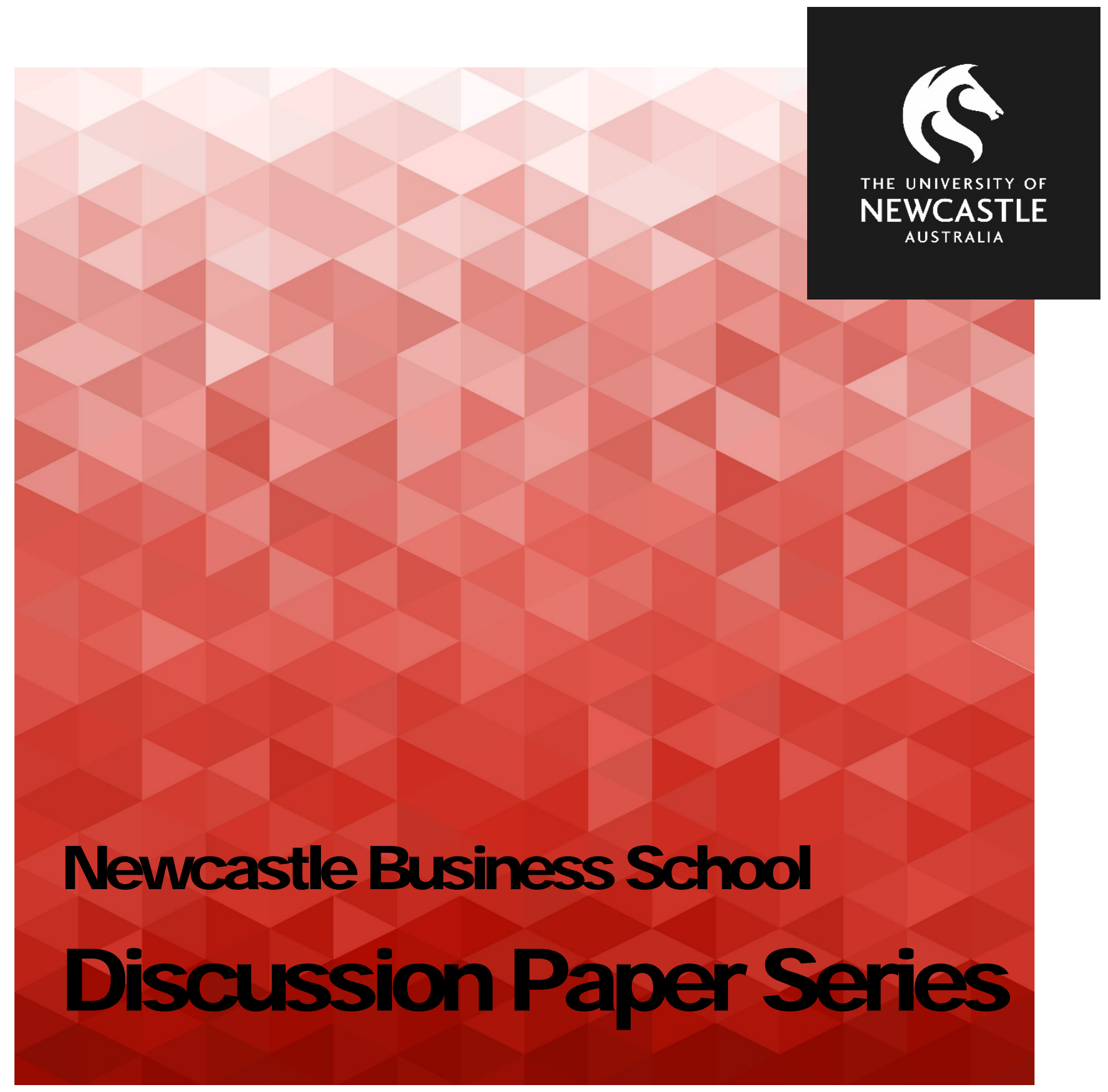

Research on the Frontiers of Knowledge

Cooperative Organizations as an Engine of Equitable Rural Economic Development

Discussion Paper 2015-01

Moris Altman 


\title{
Cooperative Organizations as an Engine of Equitable Rural Economic Development
}

\author{
Morris Altman ${ }^{1}$ \\ Dean \& Head, Newcastle Business School \\ Professor of Behavioural and Institutional Economics \\ University of Newcastle \\ Professor Emeritus \\ University of Saskatchewan, Canada \\ Email: morris.altman@newcastle.edu.au
}

March 5, 2015

\begin{abstract}
:
Cooperatives represent an alternative to large-scale corporate farms and plantations as well as to independent unaffiliated small private farms. This paper presents a comparative modeling narrative on cooperative organizational forms' potential impact on equitable rural development. This speaks to issues of both increasing the size of the economic pie and how this income is distributed. The case is made the cooperatives can potentially generate higher rates of growth and more equitable growth, even in competitive economic environments. An important type of cooperative that is focused upon in this paper is one based on the linking of smaller farms into a cooperative. Economies of scale and scope can be captured by the cooperatives and transaction costs can be reduced. Given cooperative governance, one would also expect higher levels of $x$-efficiency. Overall, cooperatives can generate relatively high incomes to cooperative members, whilst remaining competitive with the traditional privately owned large farms. Critical to the success of the cooperative, is a set rules and regulations that place them on a level playing field with the privately owned farm. In addition, the implementation and practice of cooperative principles is key to the success of the cooperative farm and rural cooperatives, more generally speaking.
\end{abstract}

JEL Classification: D02, D03, D10, D23, D33, D4, D6, D72, D74, D8, G2, I3, J00, J30, J54, J8, K2, L1, L2, L5, M5

Keywords: Cooperation, Cooperatives, Economics of Scale and Scope, Fairness, Transaction Costs, Cooperative Principles, X-Efficiency, Dynamic Efficiency, Income Equality

Discipline/research area: Economics/cooperative institutions

Field of Research codes (FoR): Divisions 14 \&16.

Socio-economic Objectives (SEO): Divisions 91 \& 97

\footnotetext{
${ }^{1}$ This paper was presented at the ICA-CCR international research conference, Cooperatives in Local and Regional Development, Pula, Croatia, June 25-28, 2014. It was also presented as a keynote address to the 9th ICA-AP Cooperative Research Conference and 2nd meeting of the ICA-AP Committee on Cooperative Research in Bali, Indonesia, September 16 2014. A version of this paper was eventually published as: Morris Altman (2015). "Cooperative Organizations as an Engine of Equitable Rural Economic Development" Journal of Co-operative Organization and Management 3: 14-23. The author thanks Louise Lamontagne and Akira Kurimoto, and conference participants for their valuable comments and suggestions.
} 


\section{Cooperative Organizations as an Engine of Equitable Rural Economic Development}

\section{Morris Altman}

\section{Introduction}

Cooperative organizational forms represent an alternative to large-scale corporate farms and plantations as well as to independent unaffiliated small private farms. Cooperatives also represent an alternative to famers as independent marketers of their products and purchasers of their inputs. This is analogous to the alternative provided by cooperatives, more generally, to traditional investor owned corporations. But what is unique to agriculture, especially in less developed economies, and also still somewhat the case in the more developed economies, is that small farms are of critical importance in agriculture whilst larger farm units often represent a competitive threat to relatively small independent family-owned farms. Cooperatives represent a means to maintain the independence of these farms. At the same time, cooperatives provide the means for these farms to remain or become competitive through producing relatively efficiently in terms of high levels of productivity per unit of input and higher levels of quality per unit of output. An alternative means of remaining competitive is for small famers to cut their real income to keep costs and thereby prices down to competitive levels. But this would reduce the farm family's standard of living and even push the family into poverty.

An important issue raised in this article is to what extent are cooperatives substitutes for traditional investor-owned farms as productive and competitive economic entities? Related to this, can cooperatives provide an alternative to the larger investor-owned farms? Can agricultural cooperatives replicate or better the assumed competitive attributes of the larger investor-owned farms? Moreover, can agricultural cooperatives deliver on economic performance whilst generating higher levels of economic wellbeing to its members as compared to what's typically on offer in the larger investor owned farm in terms income and working conditions to employees. This would be 
apart from higher levels of social wellbeing that some might derive from being a member/owner of an economically productive and sustainable cooperative.

This article presents a comparative modeling narrative on the cooperative's organizational form compared to the privately (investor-owned) owned firm's (IOF) organizational form potential impact on equitable and sustainable rural development. This speaks to issues of both increasing the size of the economic pie and how this income is distributed. The focus here is on issues most pertinent to the agricultural sector and the cooperative farm in particular, but can be extended to supply and value added cooperatives and agricultural mutuals or credit unions, for example. These arguments build upon Altman (2001 2002, 2006, 2014); Ben-Nur Jones (1995); Bowles and Gintis (2011); Chayanov (1991); Gordon (1998); Leibenstein (1966); McCain (2008); Novkovic (2006, 2007); Schultz (1964); and Williamson (2009).

It's critical to develop a modeling framework wherein one can articulate and specify the conditions under which different types of agricultural cooperatives can be sustainable in the economic realm, whilst meeting the social-economic objectives of members-where a key goal is often maintaining the economic viability and thereby the independence of the smallholder farmstead. A crucial point made in this article is that under reasonable assumptions and conditions agricultural cooperatives should be able to match the investor-owned firm in the economic domain. It also provides individuals with the opportunity to remain independent players (owners and core decision-makers) as part of a cooperative as opposed to being forced into becoming employees, often with little bargaining-power, in the investor owned farm. Related to this, cooperatives also provide smallholders with the opportunity to improve their level of material wellbeing by increasing their productivity and increasing their share of income from what it would be under traditional organizational forms.

To begin this theoretical narrative a relevant quote from the International Fund for Agricultural Development or IFAD (2011): 
Smallholder farmers gain big benefits from agricultural cooperatives including bargaining power and resource sharing that lead to food security and poverty reduction for millions, the UN Food and Agriculture Organization (FAO), the International Fund for Agricultural Development (IFAD) and the World Food Programme (WFP) stressed today on the occasion of the launch of the International Year of Cooperatives 2012 (IYC) in New York.

The importance of agricultural cooperatives in improving the lives of millions of smallholder farmers and their families cannot be overstated, the three Rome-based United Nations (UN) agencies said. Empowered by being a part of a larger group, smallholder farmers can negotiate better terms in contract farming and lower prices for agricultural inputs like seeds, fertilizer and equipment. In addition, cooperatives offer prospects that smallholder farmers would not be able to achieve individually such as helping them to secure land rights and better market opportunities.

These quotes from the world's key development agencies, specifically related to agriculture, hypothesize the advantages of cooperatives for agricultural development addressed in this article. What is crucial, however, is to provide a critical underpinning to such important hypotheses-under what conditions can agricultural cooperatives of various types be sustainable in a competitive environment. It is also important to note the significance of cooperatives in agricultural sectors throughout the world in both developed and less developed economies (Altman 2009a; ICA 2014; United Nations 2014). This speaks to the relative success of agriculture cooperatives, which requires explanation in face of the negative modeling scenarios and predictions flowing from standard economic theory. Estimates on the importance of agriculture cooperatives aren't unambiguously rigorous, but the available evidence suggests that such cooperatives are of importance to various economies' agricultural sectors. In many countries, including the United States, a large majority of farmers are members of agricultural cooperatives (ICA 2014).

\section{What's a Cooperative and Cooperative Governance?}

Prior to a formal discussion of the potential role of agricultural cooperatives, it is important to briefly define what is a cooperative and what types of cooperatives tend to characterize the agricultural landscape. A cooperative organizational form has been defined, in its modern and operational form, flowing from the Rochdale Principles, articulated in 1844 by the Rochdale Society 
of Equitable Pioneers (a consumer cooperative) in Rochdale, England. This definition has been since modified by the International Cooperative Alliance, the international governing body of cooperatives. These definitions are important because they help us to understand the organizational parameters within which cooperative decision-making takes place and helps distinguish cooperatives from the traditional investor-owned firms. This helps us to better understand why cooperatives might be superior in their decision-making outcomes to investor-owned firms. The original principles states (Rochdale Pioneers Museum 2014):

- That capital should be of their own providing and bear a fixed rate of interest.

- That only the purest provisions procurable should be supplied to members.

- That full weight and measure should be given.

- That market prices should be charged and no credit given nor asked.

- That profits should be divided pro rata upon the amount of purchases made by each member.

- That the principle of 'one member one vote' should obtain in government and the equality of the sexes in membership.

- That the management should be in the hands of officers and committee elected periodically.

- That a definite percentage of profits should be allotted to education.

- That frequent statements and balance sheets should be presented to members. The key point here is that the cooperative should be dominated by democratic governance and this should be translated into the economic realm. Revisions have made to the principles, making the rules more flexible where the Rochdale rules were seen as potentially hindering economic performance. Even with the original principles, democratic governance is vested in a somewhat hierarchical structure, that actually and in effect reduces the transaction costs of 
governance-day-to-day decisions are not made by the collective, which would be a highly timeconsuming and potentially economically inefficient process. Still, too often, the Rochdale rules of governance have been taken as the exiting rules when cooperatives' governance structures are critiqued as being incompatible with both economic efficiency and economic effectiveness, especially when cooperatives are immersed in highly competitive environments.

The Rochdale principles have evolved and modified, through the International Cooperative Alliance, to take into consideration of what's thought be required for the successful and sustainable operation of the cooperative. The current core principles of the cooperative organization form is more flexible than what's specified in the in Rochdale principles and allows for cooperative operate in a low transaction costs environment as well as forming partnerships and raising capital external to the cooperative community, conditional upon democratic control over the cooperative by cooperative members. The following summarizes the key revised cooperative principles most relevant to governance and therefore to the sustainability of cooperative organizational forms (ICA 2008):

- Democratic control by members: One person, one vote, active membership participation, and elected officials responsible to membership. This incorporates a certain decree of hierarchical leadership since members need not and typically do not engage in day-to-day decision-making (reducing transaction costs). A key point here is that members have the last say on key decisions and are well informed of elected or appointed leadership decisions (transparency).

- Democratic control of capital: Based on member contributions to cooperative’s capital (could be an equitable contribution). Part of capital is usually the common property of the cooperative. Surplus can be used for a variety of purposes as determined by cooperative members. Only part of the surplus is usually distributed to members. Surpluses can be used to build up reserves, to invest in the cooperative, and in the 
larger community. There is nothing stipulated in the rules pertinent to cooperative governance that surplus can't be entirely invested to further develop or grow the cooperative. This would be similar to the investor owned corporation where the surplus can be invested or dispersed to shareholders as dividends or to management as bonuses. Except in the cooperative, surplus allocation decisions must be made in a democratic and transparent manner.

- Autonomy and Independence: To maintain cooperatives as autonomous self-help organizations ultimately controlled by members, the terms by which cooperatives enter into agreements with other organizations, inclusive or private or public organizations, or raise capital externally (as opposed from members or surpluses) must ensure continued democratic control by members. Thus, cooperatives can linkup with non-cooperative organizations and even raise capital external to the cooperative, thereby relaxing or even removing constraints that are often assumed married to the cooperative organizational form.

- Education: Cooperative members, elected representative, managers and employees are supposed to be educated and trained so they contribute to the development of their cooperatives as cooperatives organizations.

\section{Different Types of Cooperatives}

Cooperatives can take many forms. Most pertinent to this article relates to cooperatives that represent a formal linkage or confederation of smaller farms. This allows farm families to maintain ownership over their farm, whilst cooperating in the domain of inputs (equipment and seed, for example); marketing, sales, and the distribution of output; labor pooling; value added production (processing of outputs along the supply chain), and credit (credit unions and mutuals). These forms of cooperation can generate economies in these domains without farmers losing control over their farm. Each farm becomes an equal partner in the cooperative. This can actually allow smaller farms 
to remain competitive and sustainable. This need not be the case in the absence of cooperation. This represents a type of polycentric governance structure (Ostrom et al, 1961, pp. 831-832), which is a decentralized decision-making structure linking various nodes of local control (such as the individual small farm) with higher levels of shared governance (the collective).

Moreover, being part of a cooperative might help increase the overall size of the economic pie from what is would be in the absence of cooperation and under, certain conditions, even more so than what can be achieved by much larger corporate farms (investor owned farms). In addition, given that small farm holders are analogous to the self-employed, they have the ability to capture a larger share of the economic pie than they would if they were simply employees on the larger farm or related corporations. Cooperative members have a determining say on how much they get compensated for their contributions to the cooperative. Capturing a larger share of the economic pie would also be facilitated when farmers are members of credit unions, supplier cooperatives, and value added production cooperatives. Members can accrue more direct economic benefits or revert these to their cooperative for investment purposes.

Cooperatives can also include common ownership of the farm - the more extreme form of an agricultural cooperative. In such cooperatives, economic operations could encompass agricultural production, manufacturing, and distribution. And such cooperatives can form larger cooperatives linking one to the other for the purpose of supply, distribution, and credit, for example, to capture economies of scale. The latter cooperative organizational form is exemplified by the 'classic' Kibbutz of Israel. But this vehicle for a cooperative economy completely integrates the individual into the collective or cooperative. For example, independent small famers would have to integrate themselves into this type of collective, giving up their farmstead and their economic independence. This is in contrast to cooperatives based on linking independent farmers (who remain independent) in a variety of domains as discussed above. But this more integrated cooperative provides options to farm workers to become equal partners in a cooperative, which would not exist in the agricultural 
cooperative formed by linking currently existing small farms. If you're a farm laborer, you have no farm that could form part of a cooperative. The fact that agricultural cooperatives can take on different organizational forms, provides farmers as well as farm workers with alternatives within the cooperative structure to achieve economic sustenance and independence.

\section{The Demand and Supply of Agricultural Cooperatives}

One question to be modeled is whether cooperatives are at least as efficient as investorowned firms (IOF) in agriculture. The focus here is on the more flexible cooperative wherein independent famers retain their economic independence. When at least equally efficient to the larger IOF, agricultural cooperatives would be 'economic' substitutes to investor-owned agricultural economic entities. This would be independent of any distributional impact that the cooperative might have on the coop members and the overall economy. In this case, the demand for cooperatives could then be modeled as the differential demand for alternative organizational forms where the coop is in no way inferior (in terms of efficiency) to the IOF. One would then have to determine why farmers would not join a cooperative, especially if in so doing economic benefits are generated, such as increased efficiency and increased real income.

This issue can be addressed using a basic demand and supply analytical framework. This is given in Figure 1. We assume that the demand curve for cooperatives (given by coop services) is downward sloping-price goes down, demand goes up. We assume, for simplicity, that the supply of cooperatives or coop services is given by a horizontal supply curve. In this model, given the demand curve, it is possible that the equilibrium supply of cooperatives would be marginal when the supply curve is relatively high (costs are high), such as given by D0 and SO in Figure 1. But the equilibrium

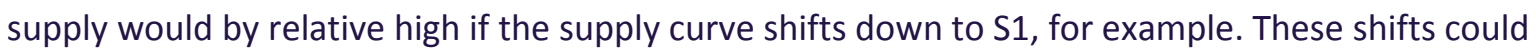
be a product of changes in the institutional costs of establishing a cooperative. Therefore, if these costs are sufficiently high, they can squeeze out the cooperative alternative from famers options. This squeezing out is both economically and socially problematic if the institutional parameters 
provide farmers or farm workers with artificially high cost cooperatives as an alternative to IOFs. This simply suggests that lowering these 'supply side' costs_creating at a minimum level playing field with IOFs can provide broader options to farmers and farm laborers. But in this scenario, when the cooperative alternative is not available, labor might be forced into IOFs, which can have serious negative implications in terms poverty, distribution, and even investment.

Both the demand and the supply side are important to determining the equilibrium number of cooperatives, controlling for the size of cooperatives. For example, if on the demand side, changes in the institutional parameters have little effect along demand curve, D2, the equilibrium level of cooperatives will remain relatively low. So the sensitivity of the demand for cooperative to price can be important. However, this being said, other demand-side factors are also of critical importance to the formation of cooperatives.

Even where demand is insensitive (or inelastic) to price, shifting the demand curve outward can play a determining role in the formation of cooperatives. For example, one can model the knowledge that potential cooperators have about the efficiency, competitiveness, sustainability, and wellbeing (including family income) effects of cooperatives, as a demand-side shift factor. If one believes that cooperatives are not sustainable or simply sustainable through farm families reducing their income to low levels, this would shift the demand curve inward, whilst a more positive set of beliefs would shift the demand curve outward. A negative set of beliefs about cooperatives can be based on false or misleading information. But if the negative beliefs do not reflect the reality of the cooperative alternative, then the demand curve is situated further to the left than it would be if more accurate and plausible information were available. Therefore, the equilibrium level of cooperatives is also a function of the beliefs of potential cooperators and whether or not these accurately reflect the socio-economic fundamentals underlying cooperatives. To the extent that cooperatives are at least as economically viable as their IOF alternative, improving the information on cooperatives to potential cooperators will shift the demand for cooperatives to the right. Such 
information can also serve to breakdown traditional normative resistance and antipathy against the cooperative organization form. A key point here is that 'false' mental models about cooperatives can reduce the equilibrium amount of cooperatives, irrespective of 'supply-side' conditions.

Another demand-side shift factor would be increasing the productivity of cooperatives. The more productive the cooperative, the further to the right should be the demand curve. Higher productivity of the small farm can be achieved, in the first instance, simply by establishing a cooperative. This is related to both the scale effect and the x-efficiency effect, discussed below. Further increases in productivity can be achieved by increasing the linkages between farm cooperatives and other cooperatives related to agriculture such as supply cooperatives and credit unions. One might end up with a demand curve such as D1. In this case, the equilibrium amount of cooperatives would be Q3 given supply curve $\mathrm{S} 1$. The demand curve could also be shifted based on the personal preferences of individuals involved in agriculture. Even given full knowledge about the efficiency of cooperatives (let's say high levels of efficiency), some individuals might simply prefer to remain independent economic agents, shifting the demand curve to the left.

A critical point to note is that even if based on objective conditions or fundamentals, the demand curve should be at D1 (this would incorporate the personal preferences of potential cooperators), the actual demand curve might only be at D0 or $\mathrm{D}^{*}$, if individuals do not have accurate information about cooperatives and if the information they have is not easily and well understood. An individual's demand for a cooperative may not reflect their true preferences, or the preferences they would have if they better and more easily understood information on cooperatives and this information was easily available-that is, at low cost and low risk.

\section{The Relative Superiority of Agricultural Cooperatives}

\section{(i) Economies of Scale and Scope and Transaction Costs}

Cooperatives can potentially generate higher rates of growth and more equitable growth, 
even in competitive economic environments. Economies can be captured through producer, purchasing and marketing coops as well as through pooled labor amongst cooperatives. Economies of scale and scope, that larger IOFs naturally benefit from, can be achieved by small farm units, through cooperation. This would make the smaller farm units linked through cooperatives, more cost competitive than the de-linked small farm units that act as independent economic agents (for a similar argument see, Valentinov 2007). Cooperative linking also allows the smaller farm units to be competitive with the larger farm units by being relatively productive. In addition, as discussed below, cooperatives facilitate higher levels of $x$-efficiency, given by the nature of cooperative governance. This provides cooperatives, potentially, with a competitive advantage over IOFs; this is apart and distinct from economies of scale and scope. As mentioned above, achieving these various economies requires an awareness of the cooperative alternative and the capability of joining/forming a cooperative.

The traditional economies of scale refer to reducing average cost by increasing the scale of output, more bananas, cocoa, sugar or wheat. Economies of scope refer to reductions in average cost that are a product of producing more than one product. Scale and scope can be facilitated through larger units of production, often identified in the agricultural sector with the larger farm entity or with larger input suppliers and distributors.

Oliver Williamson (1981, 1985, 2010), building on the work of Roland Coase (1937), developed models to explain increasing the size of the firm independent of economies of scale and scope reasons. His explanations are largely related to reducing the overall transaction costs of doing business, hence reducing average production costs. Broadly speaking, transaction costs refer to the costs of drawing-up, signing, monitoring, and enforcing of contracts. Contracts, the specification of relationships between economic agents or entities, such as firms, are key to the functioning of any economy and they can also be of an informal type. Williamson attempts to explain why increasing plant size and more often than not, firm size (multi-plant firms), is rational from the point of view of 
increasing economic efficiency.

In terms of transaction costs analyses, Williamson focuses on $(1981,1985)$ bounded rationality (BR), opportunism with guile (OG), and asset specificity (AS). For Williamson, BR refers costs incurred in the collection and processing of information. OG refers to the tendency of many individuals to deceive and cheat others in market transactions-an important aspect of the human condition, according to Williamson. AS refers to assets that once set in place, cannot be redeployed except at a significant cost to its owners or users. It is realistically assumed that assets are not like 'putty' that can be costlessly shifted from one use to another. Opportunism with guile, the proclivity of economic agents to behave dishonestly, is critical to Williamson's analysis. In a world where honesty and goodwill prevail transaction costs would be negligible. In such a world one can trust individuals to provide good quality and accurate information. Therefore, data collection and processing costs would be negligible. Moreover, asset specificity would be not be a relevant cost consideration when one's information is reasonably accurate since you're initial allocation of assets would stand a very high probability of being correct. Williamson argues that growing the size of the firm, establishing or buying out similar types of firms (horizontal integration) and establishing or buying out suppliers and distributors, is a substitute for creating honesty across economic agents. Williamson assumes that opportunism with guile should not be prevalent inside the larger corporation as the goals and objectives and decision-making are more in sync and behavior is less costly to monitor.

The traditional view in economics is that small is better in the sense that many small firms generate more competitiveness and therefore more 'efficient' economic results. Although economies of scale are part of the traditional economic toolbox, very large firms are not considered to be necessary to generate optimal scale efficiencies, hence the pursuit of scale economies should not affect the extent of competitiveness. Still, arguments persist on the advantages of getting bigger and bigger, in terms of average cost, by taking advantage of economics of scale and scope. 
Transaction cost-type analysis goes beyond any traditional scale and scope analysis, maintaining that corporate bigness reduces transaction costs significantly. But both analytical frameworks pay no heed to cooperatives as an alternative organizational structure within which economies of scale and scope and just as importantly transaction cost economies can be achieved. Moreover, given Williamson focus on opportunism with guile, cooperatives governance structure, at least as specified by the International Cooperative Alliance and discussed above, provides an incentive environment to reduce such selfish and self-serving behavior. This is another good reason to model the cooperative as an alternative to IOF in agriculture.

Cooperatives based on the linking of independent small farms, which allows for the sharing of inputs such as equipment and seed, labor pooling, sharing land when necessary (larger more efficient plots of land), storage, and the distribution of output, are all plausible economic entities. Diagram 2, illustrates the impact of cooperation as well as corporate bigness on the productivity and hence the average costs of smaller farms. In the traditional model, simply increasing firm size shifts the firm's average cost curve downward and to the right from ACs to ACL1. But through cooperation, the average cost curve also shifts downward and to the right in a similar fashion (but here from ACs* to ACL1), as the cooperative becomes the vehicle through which economies in scale and scope as well as in transaction costs can be captured. Moreover, to the extent that the recommended governance structure of cooperative might be able to better handle transaction costs, especially with regards to opportunism with guile, cooperatives might serve to shift the average cost curve to ACL2, potentially making the cooperative even more cost competitive than the IOF. Much critically depends on the actual governance structure that the cooperative adopts and implements. This modeling matches and helps explain the relative success of agricultural cooperatives even when competing with relative larger IOFs. Achieving economies in scale and scope and transaction costs does not necessarily require large and highly integrated agricultural corporations. Cooperation through linkages across farms and farmers' ownership of supply and distribution cooperatives is a viable alternative. Theoretically, there is no good reason to predict that cooperatives should fare 
worse than IOFs in terms of economies of scale and scope. The same should be true of economies related to transaction costs.

It is important to note that small farms can compete with the larger farms without becoming part of a cooperative, at least up to a point. Farmers can cut their own income as well as that of their family members working on the farm to compete on the basis of cheep labor as opposed to higher productivity, which could be achieved through joining or forming a cooperative. Famers can engage in 'self-exploitation', paying themselves below the market wage to maintain their independence. This is illustrated by a shift downward in the small farm's average costs curve from ACs to ACs*. There is evidence that cutting income to workers is often accompanied by reductions in effort inputs and therefore productivity-the efficiency wage effect. Workers retaliate against employers for being treated unfairly. But this need not occur when one has self-exploitation, where cuts to income are self-imposed to maintain ones competitive position. Small farmers can, therefore, be quite flexible in efforts to survive on the market. But the self-exploitation option is not long term optimal from the perspective of productivity or wellbeing. However, this can be the only plausible option in the absence of a viable cooperative alternative. This latter alternative can be marginalized by supply and demand side considerations, discussed above. This is inclusive of institutional impediments to cooperative development and misperceptions about the cooperative alternative amongst potential cooperators.

\section{(ii) X-efficiency}

An important theoretical concept that helps to better explain and frame the potential cooperative advantage of farmer ownership through cooperatives as opposed to corporate employment or large IOF (large farms) is x-efficiency theory. X-efficiency theory, first articulated by Harvey Leibenstein (1966), assumes, based on the evidence, that effort inputs in both its quantity and quality dimensions is a variable in the production function. Unlike conventional theory, the assumption is not made, a priori, that firms will be economically efficient independent of market 
structure and that one can assume that principle-agent problems are quickly resolved. Such presumptions generate the traditional theory's assumption that effort inputs are fixed at some level, which is often assumed to be at some maximum. But the alternative assumption of effort variability allows one to better model differential productivity across organizational forms. Given effort variability, it is possible for firms to produce less than they can potentially, given their traditional inputs (such as capital, labor, and land) and technology. When firms produce below their potential, because of relatively low levels of effort input, this is referred to as $\mathrm{x}$-inefficiency in production. Ceteris paribus, the lower the level of effort input, the higher the level of $x$-inefficiency and the lower the level of x-efficiency.

The level of x-efficiency is a product of the incentive environment facing the firm. One argument (Leibenstein 1966) is that in a less competitive environment firm management and owners prefer to invest less effort in managing the firm, reducing firm productivity and thereby increasing average production costs. This is referred to as managerial slack. Such behavior is rational from the perspective of management and owners given that such behavior serves to maximize or at least improve their level of wellbeing or utility. The higher average costs are sustainable as long as the $\mathrm{x}-$ inefficient firms are not in an optimal competitive environment or are otherwise protected from competitive pressures.

Average cost can be given by the following equation, assuming a very simple economy where labor is the only costed input (Altman 2001).

$$
\text { 1. } \quad A C=\frac{w}{\left(\frac{Q}{L}\right)} \text {, }
$$

where $A C$ is average cost, $w$ is the wage rate or, more generally, the unit cost of inputs, $(Q / L)$ is the average product of labor, $Q$ is total output, and $L$ is labor input measured in terms of hours worked. 
Anything that reduces productivity, such as managerial slack will, ceteris paribus, increase average cost.

A broader x-efficiency theoretical framework opens the door to a wide array of incentives as being important to movements in effort inputs (Altman 2001, 2002, 2006, 2009b; see also Gordon 1998; McCain 2008). This includes the incentive environment facing employees, which incorporates, wage and working conditions, affinity with and trust in the firm, substantive input in the decisionmaking process and the day-to-day operation of the firm, and evolved behavioral norms with respect to the firm. These variables can also affect managerial decision-making. Overall, these various incentives, if poorly designed and implemented will reduce effort inputs and, therefore, reduce labor productivity and possibly increase average cost. On the other hand, a well-designed incentive environment within the firm will increase effort inputs and, therefore, productivity and possibly decrease average cost. Moreover, these incentive variables affect effort inputs independent of the competitive environment. Therefore, even with imperfect competition in the product market it would be possible to have x-efficiency in production with a properly designed and implemented incentive environment. Perfect competition pressures firms into becoming more x-efficient as one decision-making option. Imperfect competition protects $x$-inefficient firms.

This modeling framework can be applied to cooperatives in general and to agricultural sector cooperatives more specifically, especially given that many of the variables that, together, impact on productivity are part and parcel of the cooperative organization form. In the managerial slack model, it is assumed that there are no changes to managerial or owner compensation as effort variability changes. It is also assumed that managerial slack (not working in the best interest of the firm), is the best behavioral assumption that can be made with regards management/owners. However, with regards to cooperatives this should not be the case. One would expect management's interest would be aligned with that the cooperative (of which management would usually be a member of) and that effective application of cooperative principles would increase the probability that this would be the 
case. But such an alignment of interests need not take place if institutional failure occurs-when the institutional environment is not conducive to minimizing managerial slack but also opportunism with guile. An appropriate incentive environment can increase the level of x-efficiency in this domain, often without increasing the cost of engaging quality management.

With regards to the larger incentive environment, here too the cooperative organizational form can provide a x-efficiency environment that is superior to what is provided by the IOF. But in this domain, improving the incentive environment comes at some cost, especially with regards to improvements in wages and working conditions. Such improvements contribute to a sense of fairness and trust across economic agents within the firm. Therefore, an improved incentive environment here positively affects both ' $w$ ' and $(Q / L)$ or productivity. And, a poorer incentive environment would typically have a negative effect on both of these variables. In this type of model, increasing the level of $x$-efficiency need not reduce average cost and reducing the level of $x$ efficiency need not increase average cost, giving the offsetting effects of changing productivity $(Q / L)$ as costs change $(w)$-see equation one. The cooperative organizational form represents one type of improved institutional environment.

One common critique of cooperatives in general is that they are more costly and must therefore be less competitive than the IOF. Therefore, being fairer and more democratic is too costly to be sustainable in a competitive market economy. Increasing ' $w$ ' increases average cost because it is assumed that effort is fixed and that there can be no offsetting x-efficiency effect on productivity. But this should not be the case in a cooperative since higher costs are part and parcel of an improved incentive environment that generate offsetting increases in productivity.

In the cooperative, average cost need not increase if the cooperative generates sufficient cost offsets in terms of $(\mathrm{Q} / \mathrm{L})$. Therefore, cooperatives need not seek competitiveness by cutting labor costs, for example. On the other hand, in the traditional model, it is assumed that competitiveness can be enhanced, unit costs are reduced, by reducing $\mathrm{w}$. But this would not be the case if lower 
wages induce sufficiently lower productivity, as workers retaliate for being treated unfairly. It is quite possible that both cooperative and fairer firms, more generally speaking, need not be either more or less competitive when effort inputs are allowed to vary with changes in the incentive environment. Changes in ' $w$ ' can always be offset by changes in productivity. More specifically, cooperatives need not be less competitive than IOFs. But the competitiveness of the cooperative is predicated on its ability to become relatively more x-efficient as costs increase or as competitive threats are mounted by IOFs.

In the traditional economic model if two firms are equally competitive, one can infer they are both equally efficient. Two firms with same quantum of traditional inputs should produce the same level of output. But in the more generalized x-efficiency model, this need not be the case since it is possible for higher ' $w$ ' firms to be more productive than low ' $w$ ' firms. Therefore two equally competitive firms need not be equally efficient. The cooperative should generate a larger economic pie even whilst it is characterized by the same average cost as the IOF. Overall, cooperative organizational forms can incentivize increases in economic or x-efficiencies, which can contribute to the process of rural economic development by increasing pie size by directly increasing, at a minimum, the material wellbeing of workers. Moreover, contrary to the traditional economic model higher cost cooperatives in terms of ' $w$ ' need not be driven out of the market by the lower cost IOFs. Some these points are illustrated in Figure 3.

In the traditional model, any increase to ' $w$ ', which is labeled for our purposes, "Costs of Being Cooperative," invariably increases average costs and is given by average cost curve CM, which relates average costs to changes in ' $w$ '. But for the cooperative firm, the increasing costs of making a firm more cooperative need not increase average given the appropriate cost offsets, through increases in productivity. So, productivity increases as immediate costs ' $w$ ' increase. This is given by d. As a consequence, it possible that average cost will not change in the faces of increases in immediate costs, which is given by c, which is horizontal up to BM or b. As immediate costs increase 
beyond $b$, average costs increase as the cooperative can't increase effort sufficiently to generate the necessary productivity cost offsets to keep average cost from rising. Effort increases hit the fall of diminishing returns. But there is a wide range of cooperativeness that is sustainable given effort variability and an appropriate incentive environment. The other side of the coin is that noncooperative firms, dominated by the IOF organizational form, need not dominate cooperative firms in terms of competitiveness. Moreover, to the extent that technological change is motivated by the higher immediate costs of becoming more cooperative, this has the effect of shifting the cooperative firm's average cost curve to BMT (Altman 2009b). This provides cooperatives with an additional degree of freedom in dealing dynamically, over time, with immediate cost pressures in a planned and systematic manner.

At this point, it important discuss the point that cooperatives are more flexible organizations when it comes to dealing with economic shocks than is the traditional IOF. As already discussed independent small farmers can drive their income down to quite low levels to maintain their competitive position against larger farms. Of course, farmers don't respond to their self-exploitation by retaliating against themselves by reducing their efforts inputs and thereby their productivity. This same narrative can be applied to cooperatives where farmers are in effect owner-operators who are cooperators. However, when large IOF (farms) attempt to cut wages to become more competitive, productivity might very well diminish. This argument can modeled through the prism of the efficiency wage literature, where it is assumed in its most contemporaneous version, that effort is a positive function of wages up to some maximum wherein average costs are minimized and rates of profits are maximized. This is referred to as the efficiency wage. It is argued that wage are sticky downward at this wage since cutting the wage, for example, during an economic recession or company crises, will result in workers retaliating against being treated unfairly by reducing their effort inputs thereby increasing average cost. Related to this, workers will lose trust in their employers causing workers to locate other jobs when and where possible, increasing job turnover and further increasing average cost (Akerlof 1982; Akerlof and Yellen 1990; Bewley 1999). 
In Figure 4 these points are illustrated by efficiency wage curve EW, which is subject to diminishing returns with regards to changes in the wage rate. The efficiency wage is given by $w^{*}$. The important point to be made here is that in cooperatives if the wage and other benefits need to be reduced, it unlikely that cooperators will cut effort inputs in response, hence if wages are reduced below $\mathrm{w}^{*}$, one can assume a perfectly elastic productivity curve at point a. Any reduction in wages would not effect the cooperatives' productivity. Cooperatives are unlikely to be subject to the efficiency wage effect whereby workers reduce effort input when wage and/or working conditions deteriorate.

Therefore, in face of economic shocks, workers (coop members) can reduce their own economic compensation without retaliated (against themselves) for cutting such compensation. For this reason, cooperatives are more flexible than IOFs in face of price shocks, for example, which are very common in agriculture. They can better survive a crisis and also maintain employment by cutting own real income during economic crisis (Tremlett 2013). They can also reduce wages and other benefits to redirect these funds to investment purposes, providing cooperatives with an additional degree of freedom in the investment domain.

\section{Cooperatives, Income, and Surplus}

Because of the potential efficiency advantage of cooperatives over independent small farms, they should yield higher incomes to farmers than the independent farmers might accrue, thus increasing the extent of poverty reduction that might otherwise occur. Based on implementing and adhering to principles of cooperative governance, one would expect that cooperative members should, on average, earn higher incomes than small independent farmers. This is related to cooperatives capturing economies of scale and scope as well as reducing pertinent transaction costs. Moreover, given effort variability, cooperatives can generate higher levels of x-efficiency, allowing for both higher income and cost competitiveness.

One would also expect that cooperatives would yield higher incomes to rural agricultural 
workers (when they are cooperative members) than they would earn as employees of privatelyowned farms large or small. This is related to and affected by the bargaining power of rural workers and related to this the rules of the game as they apply to labor organizations-are rural workers organized in unions, for example. To extent that farm workers have few legal rights to organize one would expect, based on the generalized x-efficiency theory discussed above, farm workers would be relatively low paid, unless employers are sympathetic with the wellbeing of their employees through a sense of moral sentiments and responsibility. So, improved bargaining power can provide farm workers with higher income and incentivize higher level of x-efficiency in the larger IOF. But being part of a cooperative provides farm laborers with the capability to achieve higher levels of material wellbeing given the innate decision-making mechanism, if enforced, in the cooperative organizational form.

It is important note that the higher productivity in cooperatives as compared to the smaller farms, not only allows for higher income to farmers but higher levels of surplus-a residual that can be used for investment. It can also be returned to members as a bonus or dividend or invested in ones community. The cooperative also has potentially an efficiency advantage over the larger farm through $\mathrm{x}$-efficiency and it's greater capacity to reduce transactions cost most closely associated with opportunism with guile. The higher productivity of the cooperative can generate a higher surplus, even when cooperators are paid more than wage laborers. To some extent that surplus is determined in part by the compensation directed to management included CEOs and CFOs. One advantage of cooperatives is such payments can be significantly less than what are paid by IOFsmuch depends on the extent to which cooperatives apply principles of equity and fairness to their governance structure and practice. But in principle, cooperatives are not at a disadvantage in providing internal sources of income for investment purposes. Of course, some cooperatives are turning to the market or government to source funds for investment.

Some these points are illustrated in Figure 5. The small farm is the weakest economic link in 
the system with regards to surplus generation. But unlike what would be expected in the traditional economic model, the cooperative is not at a disadvantage when compared with the larger farms. To the extent that cooperatives have an advantage, this is related to both higher levels of efficiency and a lesser share of income going to management.

\section{Conclusion}

The evidence is consistent with the viability and the sustainability of agricultural cooperatives. This needs to be and is modeled in this article. This includes specifying the conditions under which cooperatives can be established and fostered. We employ institutional analysis, $x$-efficiency theory, efficiency wage theory, and transaction cost analysis, to this end.

Cooperatives are not necessarily superior to IOFs in terms of competitive economic entities. But cooperatives should not be modeled as a high cost alternative to investor owned firms or farms. Cooperatives provide a viable alternative to the typically hierarchical IOF. Cooperatives provide small farmers as well as agricultural workers with the means to capture economics of scale and scope as well as to reduce transaction costs in a manner that is at least equal to what can be achieved by the larger privately-owned farm. In addition, agricultural cooperatives can better and more easily achieve higher levels of $x$-efficiency and more easily reduce transaction costs related to opportunism with guile. This is related, in theory, to the governance structure, that one would expect, in theory, to dominate the cooperative.

Cooperatives also provide advantages in terms of the income that can be secured by members. Cooperative members, themselves decide the share of total output, inclusive of surplus, that they will secure. In the IOF, decisions on the distribution of income are determined by owners who usually are delinked from members in terms of preferences and knowledge of the size of the economic pie. In the IOF, the distribution of total output depends on the bargaining power of workers, which is contingent on the laws related to union organization and collective bargaining being conducive to such collective action. Also cooperatives have additional degrees of freedom in 
terms of being able allocate income away from member payments or wages to investment purposes as part of the democratic decision-making process. Given that this is a form self-exploitation, there would be no expected negative effect on x-efficiency (efficiency wage effect) in the cooperative as there would be in the IOF.

Cooperatives will not be the choice of all agents given the risks involved in establishing and maintaining cooperatives. As discussed above (The Demand and Supply of Agricultural Cooperatives), this helps explain why cooperatives are not even more economically significant than they already are. But if the cooperatives alternative is available and understood in terms of economic sustainability and risk, it provides a more objective option to famers and farm laborers as well as workers in the agricultural sector. More individuals might choose the cooperative alternative if they have a better understanding of what this alternative to the IOF entails. The cooperative option in governance, production, and income distribution needs to be appropriately framed so as to provide real options to decision makers. This is especially the case in a world of imperfect, asymmetric, and biased information.

Overall, the viability of cooperative is a function of the institutional rules of the game within which cooperatives must operate. But the same is the case of IOF. If the institutional parameters are not appropriate, it becomes difficult to establish cooperatives, and cooperatives can be squeezed out of the agricultural sector for institutional as opposed to economic efficiency reason. Therefore, at a minimum, an equal institutional playing field between agricultural cooperatives and IOFs in agriculture must exist for cooperatives to become a viable and plausible choice amongst farmers and farm workers.

The predicted advantages of agricultural cooperatives are very much a function on whether or not and extent to which cooperative principles are employed to underpin cooperative governance. Transparency and accountability are critical ingredients of cooperative success. Also, important is having a robust and tested business plan and competent and qualified individuals leading the 
organization-just like with a successful IOF. Cooperatives typically do not survive if they are economically poorly managed and build upon an unsustainable business plan. Cooperative principles should help make a robust business plan a success. But cooperative principles without such a plan, stands little chance of success.

Some of the key points made in this article are summarized in Figure 6. Given the appropriate institutional environment agricultural cooperatives should be associated with higher levels of $x$ efficiency and higher levels of labor income, both of which are causally related. This higher labor income should result in cooperatives contributing more to poverty reduction than IOFs. The larger farm (IOF) should be associated with lower levels of x-efficiency and lower levels of labor income, but the latter is contingence on workers' bargaining power and the preferences of employers. The cooperative organizational form allows smaller farms to take advantage of economies of scale and scope and in transaction costs, which the larger IOFs are able to achieve by the nature of their size. All told, cooperatives should be cost competitive with the larger IOFs even whilst providing higher levels of economic benefits to their members. The smaller farm unit should be relatively high cost, but can survive, as discussed above, through self-exploitation.

It is critical to reiterate the subtext underlying predicting cooperative success in agriculture:

i. Exogenous institutions (laws, rules, and regulations) that provide cooperatives with an equal playing field with IOFs;

ii. Implementing and maintaining cooperative principles in operating the cooperative;

iii. Good economic governance in the context of cooperative principles.

iv. Qualified individuals operating the cooperative in the context of cooperative principles (requires cooperative education and hiring and promotion based on merit). 


\section{References}

Akerlof, G.A. (1982). “Labor Contracts as Partial Gift Exchange.” Quarterly Journal of Economics 97: 543-569.

Akerlof, G.A. and J.L. Yellen (1990). "The Fair Wage Hypothesis and Unemployment." Quarterly Journal of Economics 105: 255-283.

Altman, M. (2001). Worker satisfaction and economic performance. Armonk, NY: M.E. Sharpe.

Altman, M. (2002). "Economic Theory, Public Policy and the Challenge of Innovative Work Practices," Economic and Industrial Democracy: An International Journal, Vol. 23: 271-290.

Altman, M. (2006). “Workers Cooperatives as an Alternative Competitive Organizational Form," Advances in the Economic Analysis of Participatory and Labor-Managed Firms, 9: $213-235$.

Altman, M. (2009a). "History and Theory of Cooperatives," in International Encyclopedia of Civil Society, edited by Helmut Anheier \& Stefan Toepler. New York: Springer.

Altman, M. (2009b). “A Behavioral-Institutional Model of Endogenous Growth and Induced Technical Change," Journal of Economic Issues, 63: 685-713.

Altman, M. (2012). Behavioral Economics For Dummies. Wiley: New York.

Altman, M. (2014). “Are Cooperatives a Viable Business Form? Lessons from Behavioural Economics." In Sonja Novkovic and Tom Webb, eds. Co-operatives in a Post-Growth Era: Towards Co-operative Economics. London: ZED Books.

Ben-Nur, A., and D. Jones (1995). “Employee participation, ownership, and productivity: A theoretical framework," Industrial Relations 34: 532-554. 
Bewley, T.F. (1999). Why Wages Don't Fall During a Recession. Cambridge MA: Harvard University Press.

Bonin, J. P., D.C. Jones, and L. Putterman, (1993). “Theoretical and empirical studies of producer cooperatives: Will ever the twain meet?" Journal of Economic Literature 31: 1290-1320.

Bowles, S. and H. Gintis (2011). A Cooperative Species: Human Reciprocity and Its Evolution. Princeton, N.J.: Princeton University Press.

Chayanov, A.V. (1991). Theory of Peasant Cooperatives, first published, 1926. Columbus, OH: Ohio State University Press.

Coase, R. (1937). "The Nature of the Firm," Economica 4 : 386-405.

Doucouliagos, C. (1995). “Worker participation and productivity in labor-managed and participatory capitalist firms: A meta-analysis," Industrial \& Labor Relations Review 49: 58-77.

Ellis, F. and S. Biggs (2001). “Evolving Themes in Rural Development, 1950s-2000s," Development Policy Review 19: 437-448.

Gordon, D. M. (1998). “Conflict and cooperation: An empirical glimpse of the imperatives of efficiency and redistribution," in E. O. Wright (Ed.), Recasting egalitarianism: New rules for communities, states and markets. London/New York: Verso: 181-207.

Hazlehurst, J. (2014). "What Hope For Mutuals After The Co-Op?” Management Today. Available at: http://www.managementtoday.co.uk/news/1291217/what-hope-mutuals-co-op/.

ICA (2008). What is a co-operative? . Available at: http://www.ica.coop/coop/index.html\#difference.

ICA (2014). "Co-operative Facts and Figures." Available at: http://ica.coop/en/whats-co-op/cooperative-facts-figures.

IFAD (2011). "Agricultural Cooperatives are Key to Reduce Hunger and Poverty." Available at: http://www.ifad.org/media/press/2011/76.htm. 
Leibenstein, H. (1966). "Allocative efficiency vs. 'x-efficiency'." American Economic Review 56: 392415.

McCain, R. A. (2008). “Cooperative games and cooperative organizations," Journal of SocioEconomics, doi:10.1016/j.socec.2008.02.010.

Novkovic, S. (2006). "Co-operative business: The role of co-operative principles and values.," Journal of Co-operative Studies 39:15-16.

Novkovic, S. (2007). “R\&D, Innovation and Networking: Strategies for cooperative survival," Advances in the Economics of Participatory and Labour Managed Firms 10: 205-233.

Ostrom, V., et al., (1961). The organization of government in metropolitan areas: a theoretical inquiry. American Political Science Review 55: 831-842.

Rochdale Pioneers Museum (2014). "Rochdale Principles." http://www.rochdalepioneersmuseum.coop/about-us/the-rochdale-principles. Accessed August 21, 2014.

Schultz, Theodore W. (1964). Transforming Traditional Agriculture, New Haven: Yale University Press.

Sexton, R.J. and Iskow, J. (1993). "What Do We Know About the Economic Efficiency of Cooperatives: An Evaluative Survey," Journal of Agricultural Cooperation, 8: 15-27.

Tremlett, G. (2013). “Mondragon: Spain's Giant Co-Operative Where Times Are Hard But Few Go Bust," The Gaurdian. Available at: http://www.theguardian.com/world/2013/mar/07/mondragon-spains-giant-cooperative.

United Nations (2014). "Background Paper on Cooperatives." Available at: http://www.un.org/esa/socdev/social/cooperatives/documents/survey/background.pdf. 
Vladislav V. (2007). "Why are cooperatives important in agriculture? An organizational economics perspective," Journal of Institutional Economics, 2: 55-69.

Williamson, O.E. (1981). "The Modern Corporation: Origins, Evolutions, Attributes," Journal of Economic Literature 19: 1537-1568.

Williamson, O.E. (1985). The Economic Institutions of Capitalism: Firms, Markets, Relational Contracting. New York, NY: Free Press.

Williamson, O.E. (2010). "Transaction Cost Economics: The Natural Progression," American Economic Review 100: 673-90. 
Figure 1

Demand and Supply for Cooperatives

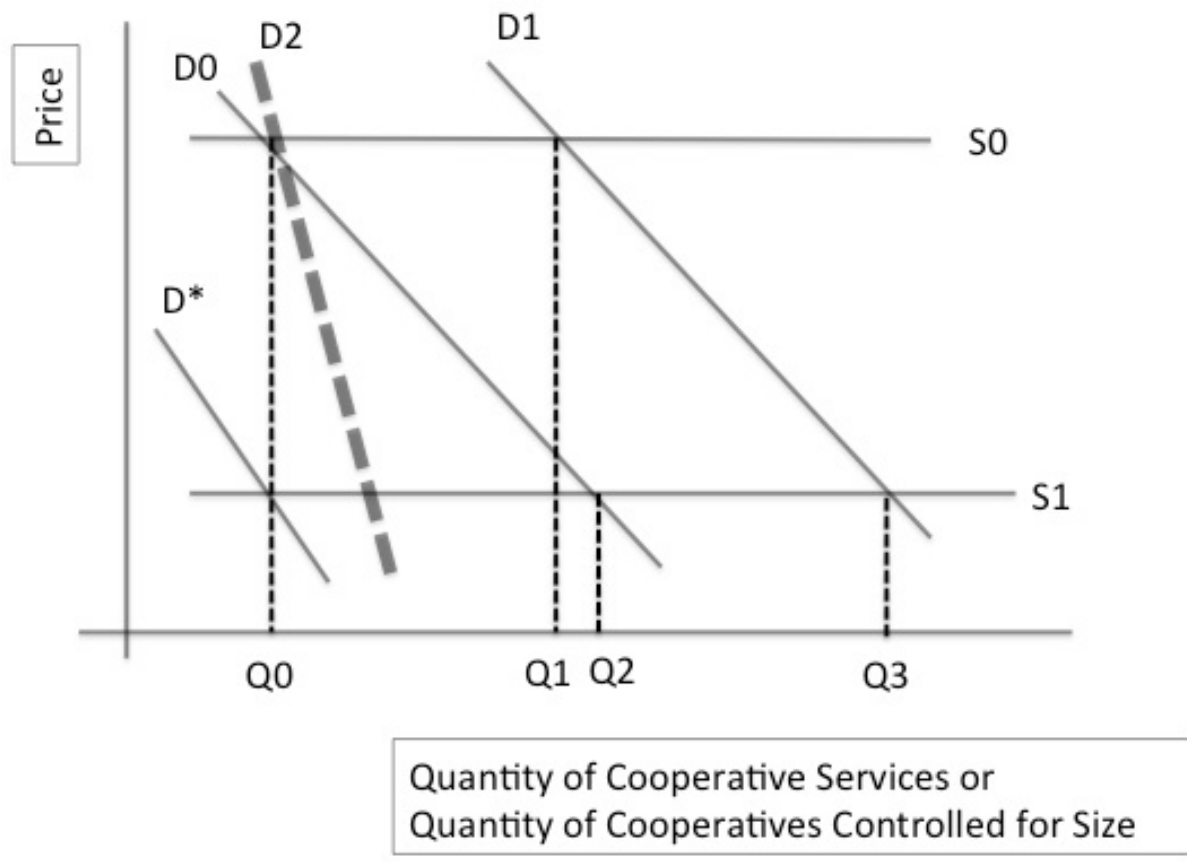


Figure 2

\section{Scale Economies and Organizational Types}

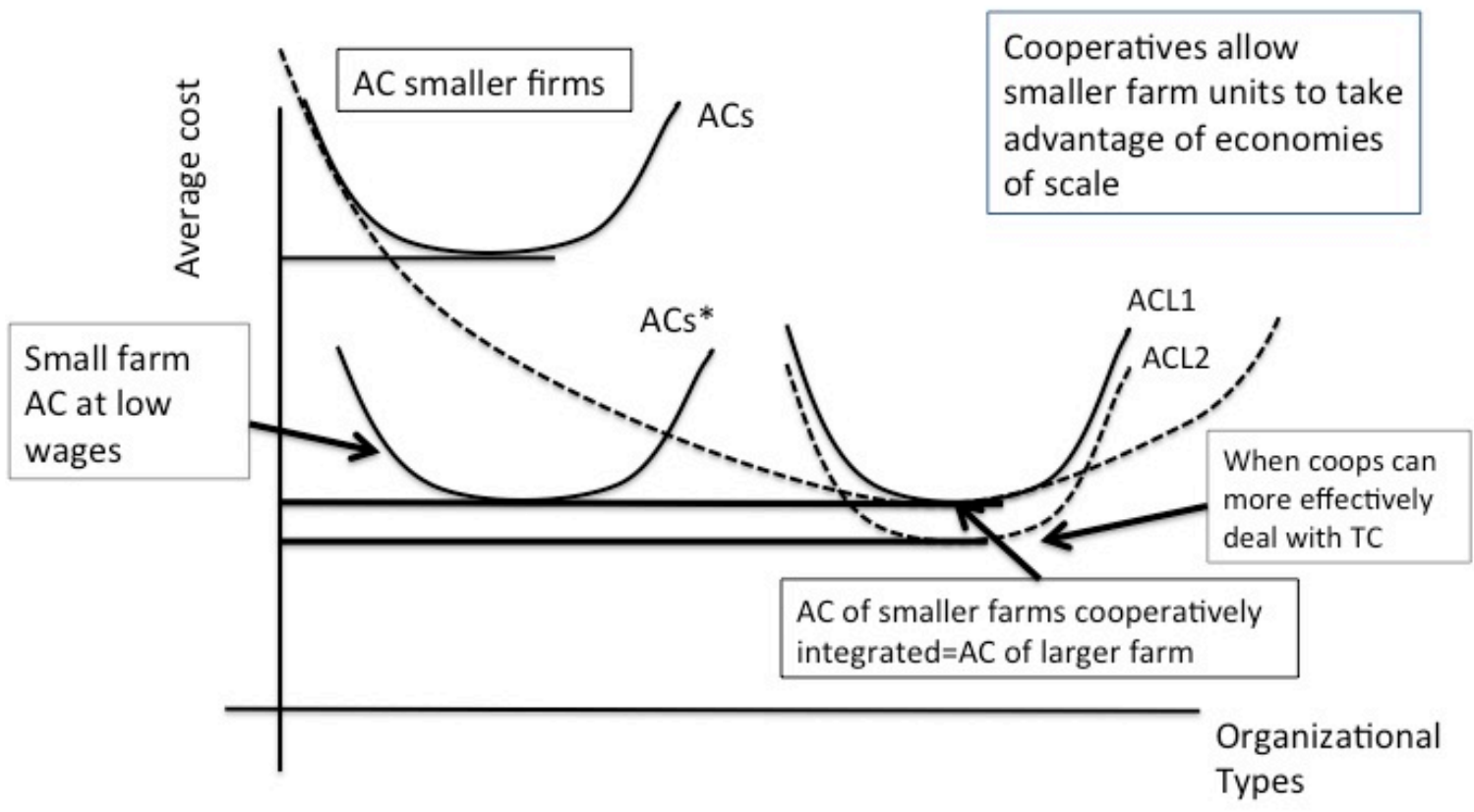


Figure 3

\section{Unit Production Costs and Cooperatives}

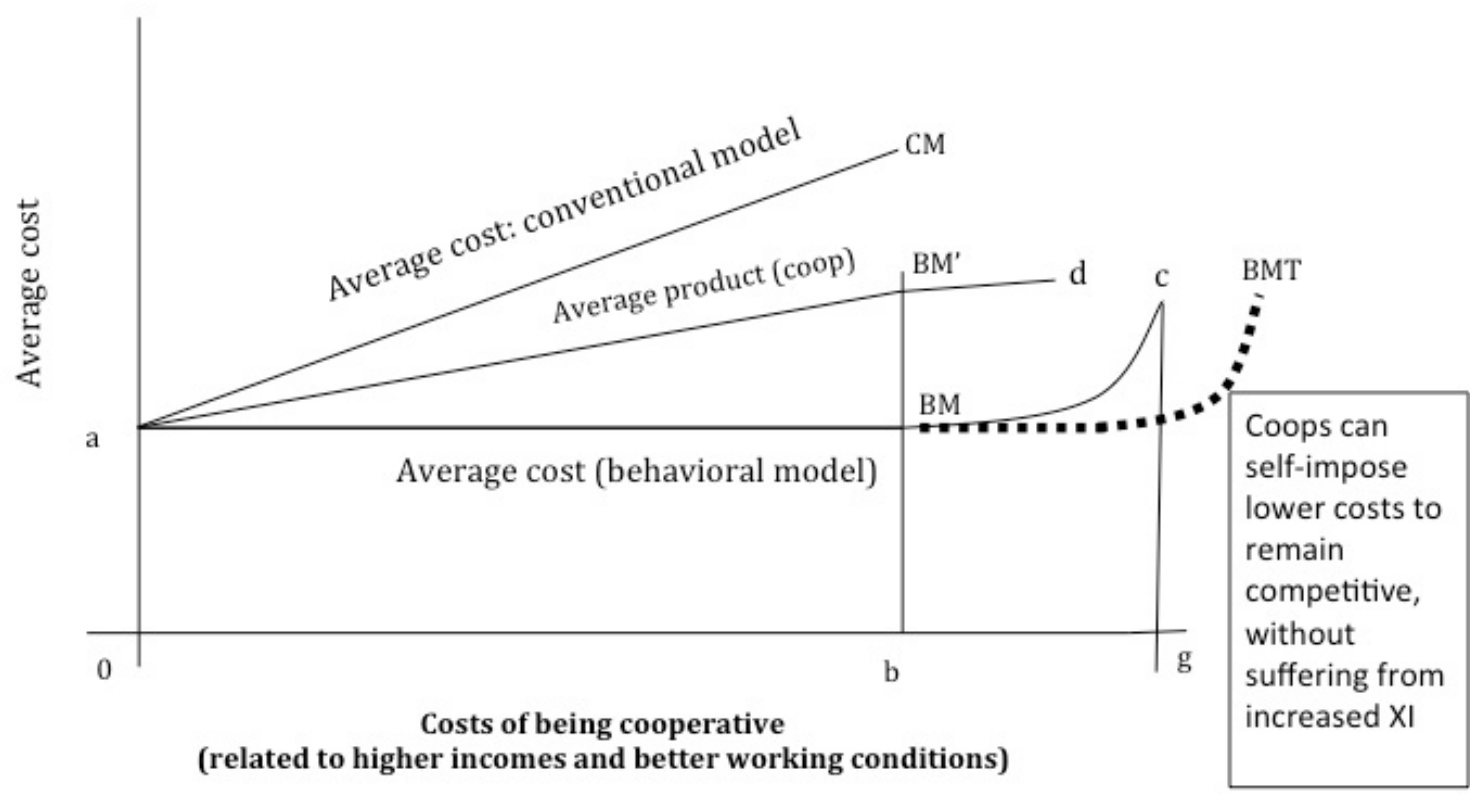


Figure 4

\section{Coop vs IOF Efficiency Wages}

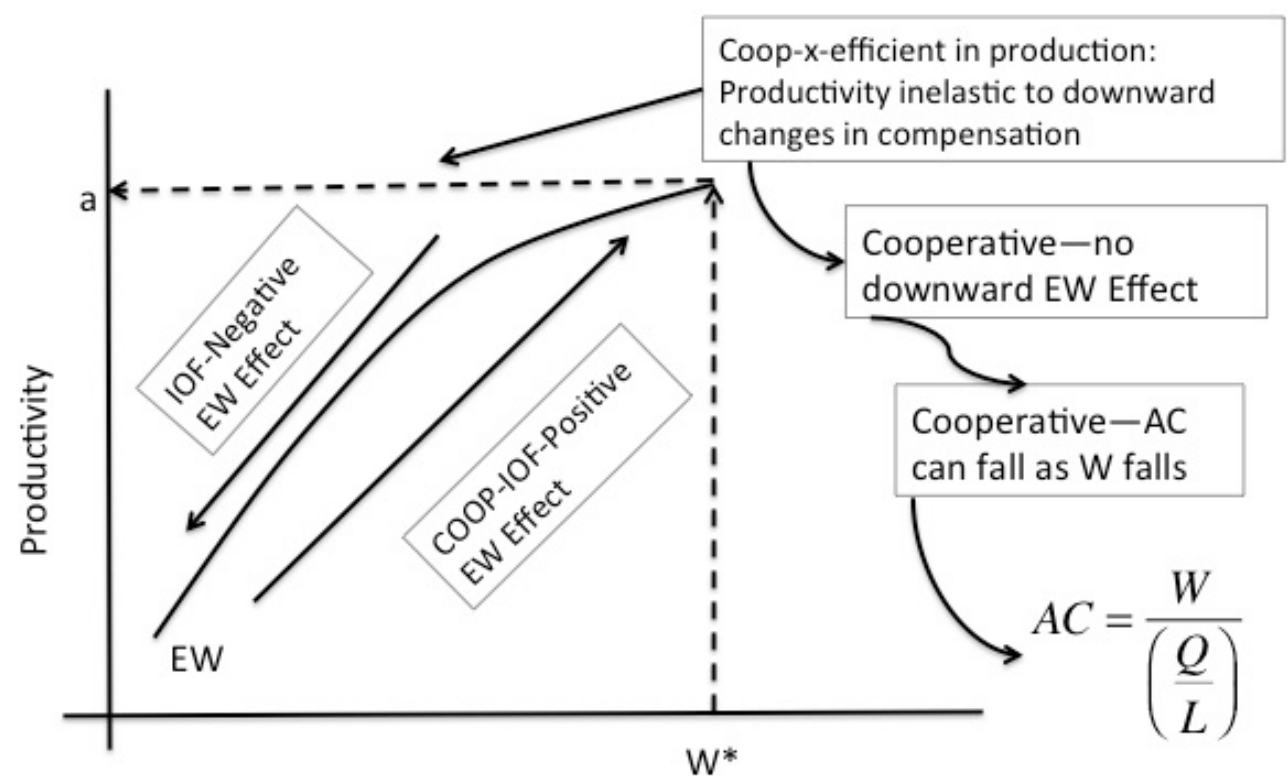

Agent compensation 
Figure 4

\section{Coop vs IOF Efficiency Wages}

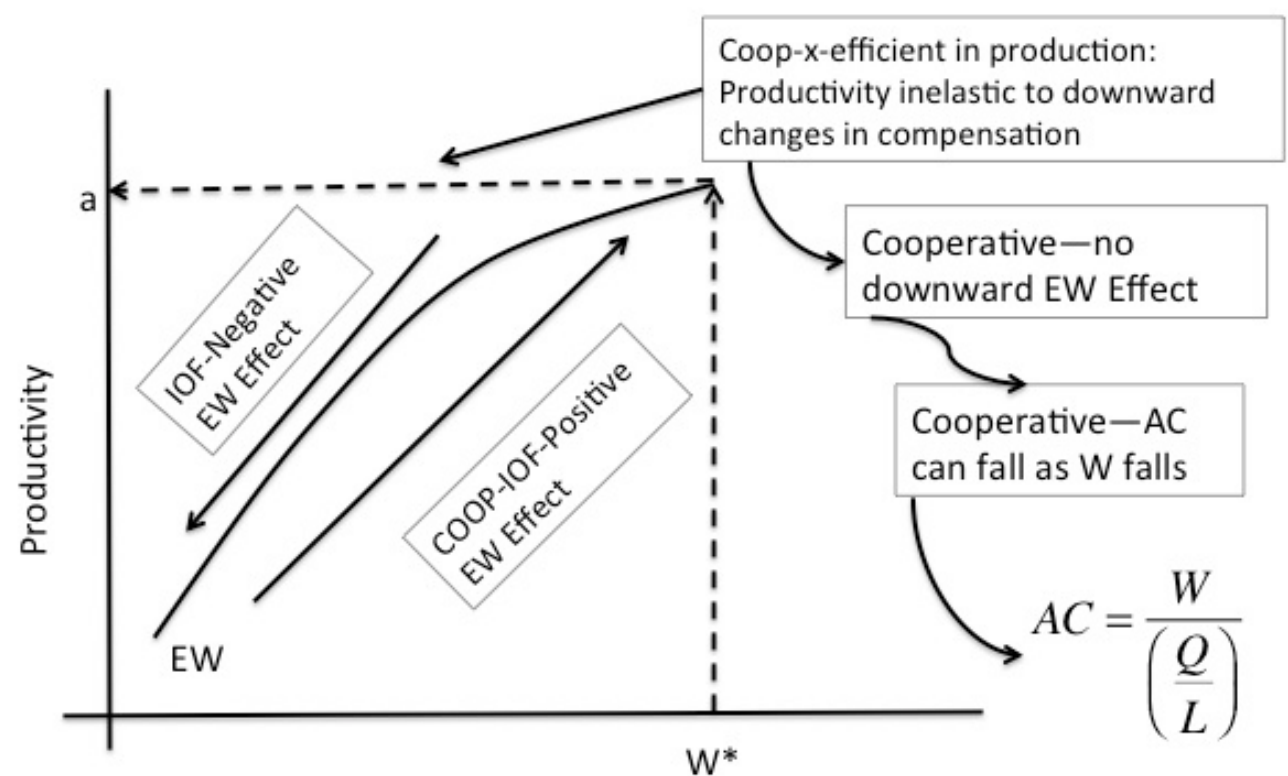

Agent compensation 
Figure 5

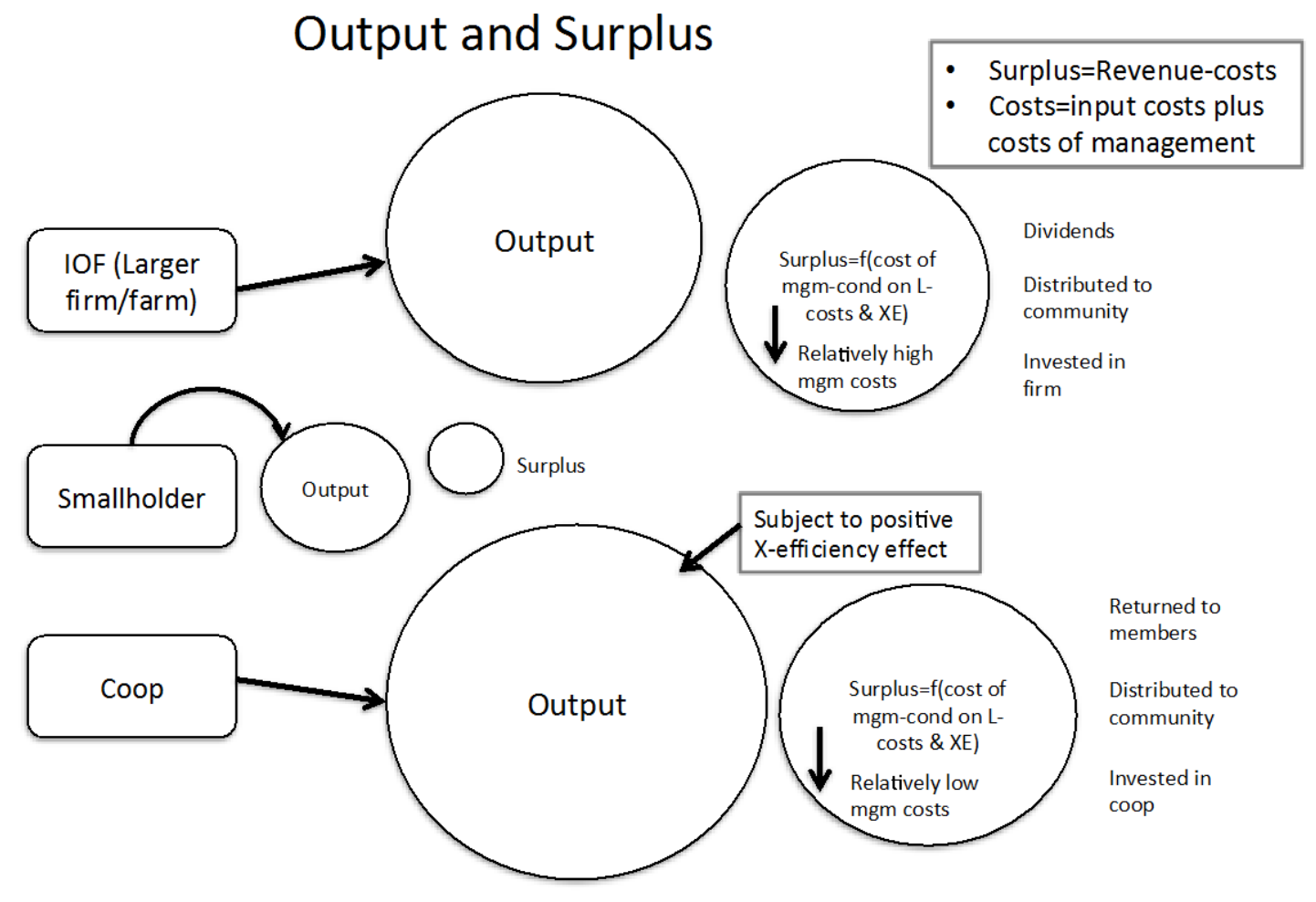


Figure 6

\section{Agriculture and Coops}

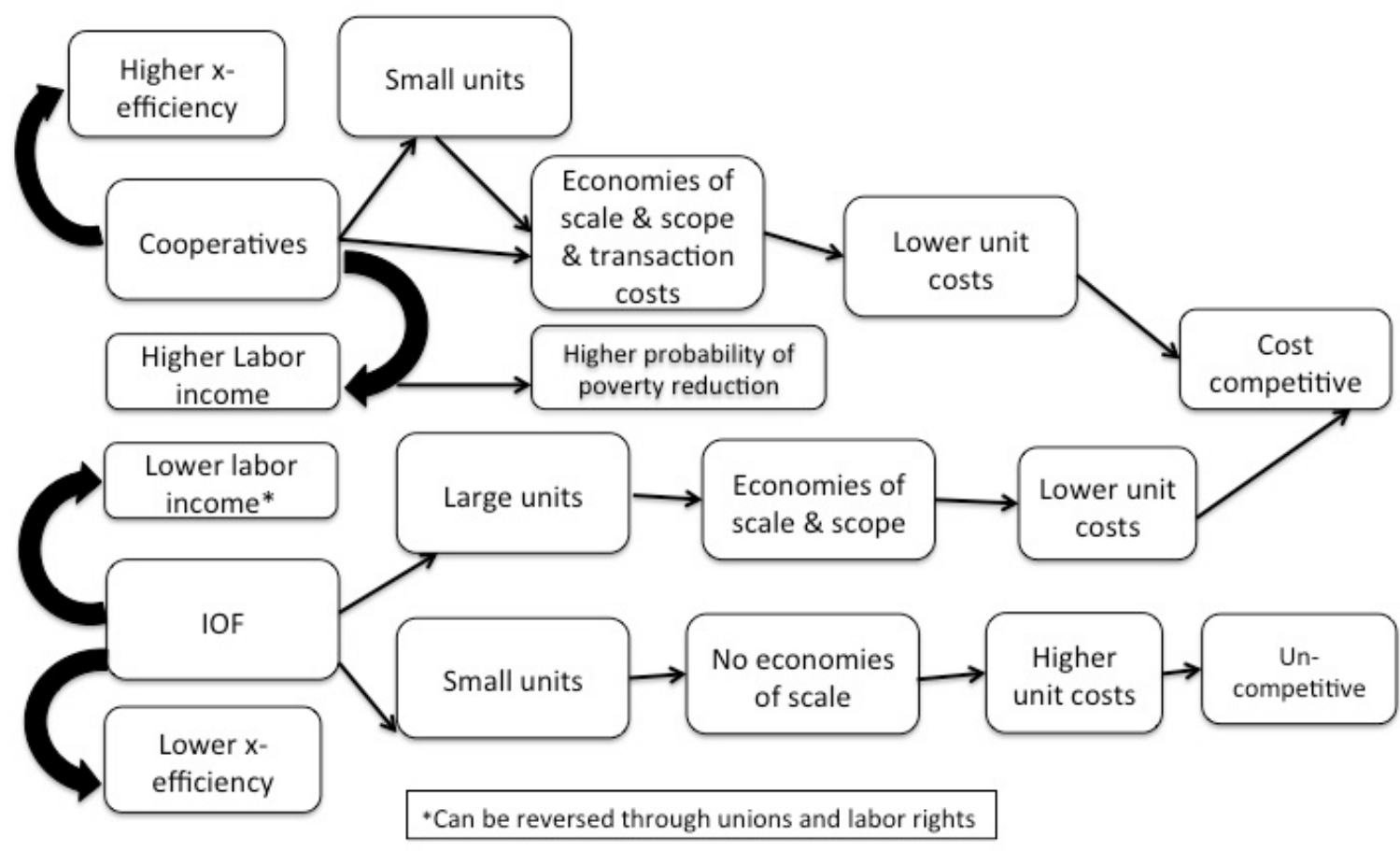

